\title{
Rapid growth and sterility of growth hormone gene transgenic triploid carp
}

\author{
YU Fan ${ }^{1}$, XIAO Jun ${ }^{1}$, LIANG Xiang Yang ${ }^{1}$, LIU ShaoJun ${ }^{1 *}$, ZHOU GongJian ${ }^{1}$, LUO KaiKun ${ }^{1}$, \\ LIU Yun ${ }^{1}$, HU Wei ${ }^{2}$, WANG YaPing ${ }^{2} \&$ ZHU ZuoYan ${ }^{2 *}$ \\ ${ }^{1}$ Key Laboratory of Protein Chemistry and Fish Developmental Biology of Education Ministry of China, College of Life Sciences, Hunan Normal \\ University, Changsha 410081, China; \\ ${ }^{2}$ State Key Laboratory of Freshwater Ecology and Biotechnology, Institute of Hydrobiology, Chinese Academy of Sciences, Wuhan 430072, China
}

Received February 13, 2011; accepted March 1, 2011

\begin{abstract}
Triploid carp (100\%) with $150(3 \mathrm{n}=150)$ chromosomes were obtained by crossing the females of improved tetraploid hybrids ( + , $4 n=200)$ of red crucian carp (o) $\times$ common carp $\left(0^{\star}\right)$ with the males of diploid yellow river carp $\left(0^{\star}, 2 n=100\right)$. The crosses yielded transgenic triploid carp (positive triploid fish, $44.2 \%$ of the progeny) and non-transgenic triploid carp (negative triploid fish). Histological examination of the gonads of 24-month-old positive triploid fish suggested they were sterile and the fish were not able to produce mature gametes during the breeding season. Morphologically, both the positive and negative triploid fish were similar. They had a spindle-shaped, laterally compressed, steel grey body with two pairs of barbells. Most of the quantifiable traits of the triploid carp were intermediate between those of the two parents. The positive and negative triploid fish were raised in the same pond for 2 years. The mean body weight of the positive triploid fish was 2.3 times higher than the negative triploid fish. The weight of the largest positive triploid fish was 2.91 times higher than that of the largest negative triploid fish. Thus, we produced fast-growing transgenic triploid carp that have a reduced ecological risk because of their inability to mate and produce progeny.
\end{abstract}

transgene, carp, diploid, triploid, improved tetraploid hybrids of red crucian carpxcommon carp, sterility, ecological safety

Citation: $\quad$ Yu F, Xiao J, Liang X Y, et al. Rapid growth and sterility of growth hormone gene transgenic triploid carp. Chinese Sci Bull, 2011, 56: 1679-1684, doi: 10.1007/s11434-011-4446-7

There have been substantial advancements in the development of transgenic commercial fish [1] in America, Canada and China. For example, researchers have produced transgenic carp that have an additional "all-fish" growth hormone gene [2], transgenic Atlantic Salmon (Salmo salar, and transgenic coho salmon (Oncorhynchus kisutch) [3,4]. Despite these advances, transgenic fish have never been successfully commercialized. The primary bottleneck for the use of transgenic fish is the concern about potential ecological safety. If transgenic fish were able to hybridize with a related species in the wild, it is possible that the transferred genes would pollute the wild gene pool and destroy species variety [5]. The only way to address this issue

*Corresponding authors (email: 1sj@hunnu.edu.cn; zhuzy@nsfc.gov.cn) is to control the fertility of transgenic fish. Thus, there has been an increase in research interest into the mechanism by which the fertility of transgenic fish can be controlled. There is no doubt that the production of sterile triploid transgenic fish will address concerns about ecological risk.

The College of Life Sciences at Hunan Normal University and cooperating institutions have successfully established a population of bisexual fertile tetraploid red crucian carp hybrids $(4 n=200)$ [6-8]. This population has been maintained for 18 generations $\left(\mathrm{F}_{3}-\mathrm{F}_{18}\right)$. In recent years, a population of improved tetraploid red crucian carp hybrids $[9,10]$ was obtained using gynogenetic methods. Both the tetraploid red crucian carp hybrids and the improved tetraploid red crucian carp hybrids were able to reproduce and both possessed stable genetic characteristics. Hybridization 
between the tetraploids and diploid fish species produced all-triploid progeny with three forms of abortive gonads, including sterile ovarian ovary-like, sterile testis-like, and sterile fat-like forms [11]. The development of tetraploid red crucian carp hybrid and improved tetraploid red crucian carp hybrid populations has ensured the availability of sufficient parents for producing fertile triploid fish on a large scale. Thus, crossing tetraploid red crucian carp hybrids and diploid transgenic carp should yield 100\% sterile triploid progeny. If true, this would alleviate public concerns about the potential ecological safety of transgenic fish commercialization. We crossed improved tetraploid red crucian carp hybrids with diploid transgenic yellow river carp that possessed an additional grass carp growth hormone gene $(G C G H)$. We obtained transgenic triploid carp (positive fish) and non-transgenic triploid carp (negative fish). We then evaluated the growth and reproductive development of these progeny. Our results offer insight into the expectation for successfully commercializing $G H$ gene transgenic carp.

\section{Materials and methods}

\subsection{Experimental materials}

We obtained transgenic diploid yellow river carp $(2 \mathrm{n}=100)$ from the State Key Laboratory of Freshwater Ecology and Biotechnology, Institute of Hydrobiology, Chinese Academy of Sciences. These fish carried the grass carp growth hormone gene (abbreviated $\mathrm{CAgcGH}$ ) and were the heterozygotes of the 3 rd generation. We also obtained improved tetraploid red crucian carp hybrids $(4 n=200)$ from the National Resources Protection Base of Tetraploid Fish.

\subsection{Experimental methods}

We selected sexually mature male transgenic diploid yellow river carp $(2 \mathrm{n}=100)$ and female improved tetraploid red crucian carp hybrids during the breeding season of 2008. These adults were artificially induced and the gametes were collected and fertilized. The fertilized eggs were incubated in a glass container with water at $(20 \pm 2)^{\circ} \mathrm{C}$ until hatching. We obtained a total of 10000 triploid fry. On April 20, 2008, the fry were transferred to a $28-\mathrm{m}^{2}$ cement pond and reared until they reached $3 \mathrm{~cm}$ in length. Seven days later, we randomly collected 500 juvenile fish of equal body size and transferred them into a $1200-\mathrm{m}^{2}$ experimental earthen pond for further rearing. The progeny were fed with commercial carp feed. A random sample of the progeny was collected each month to measure growth rates and check for the presence of $\mathrm{CAgcGH}$.

\subsection{Total DNA extraction}

In April 2009, we collected 15 of the 12-month-old hybrid progeny from the experimental pool. These fish were euthanized and blood was collected from the caudal vein of each individual. We used acid citrate glucose solution (abbreviated ACD) to prevent coagulation of the blood samples. We isolated total DNA from blood cells using a UNIQ210 DNA Extraction Kit (Sangon, Shanghai, China), following the manufacturers protocol. The total DNA samples were stored at $-20^{\circ} \mathrm{C}$ after checking for quality and purity.

\subsection{CAgcGH detection}

The transgenic triploid fish (positive fish) and the nontransgenic triploid fish (negative fish) were identified by specific PCR amplification of a 328-bp fragment of the grass carp growth hormone gene from genomic DNA samples that were obtained. The primer sequences were as follows: P(+): 5'-CATTTACAGTTCAGCCATGGCTAGA-3', P(-): 5'-AGCACCACCGACAACAGCACTAATG-3'.

The PCR cycling conditions were: $94^{\circ} \mathrm{C}$ for $5 \mathrm{~min} ; 35$ cycles of $94^{\circ} \mathrm{C}$ for $30 \mathrm{~s}, 60^{\circ} \mathrm{C}$ for $30 \mathrm{~s}$, and $72^{\circ} \mathrm{C}$ for $30 \mathrm{~s}$; and a final extension for $10 \mathrm{~min}$ at $72^{\circ} \mathrm{C}$. We examined an additional 253 triploid hybrid progeny in November 2009.

\subsection{Measurement of total genome DNA content}

We measured the DNA content of red crucian carp, transgenic triploid carp, and non-transgenic triploid carp. We collected red blood cells from the caudal vein of the common carp for use as a control. The DNA content was measured using a flow cytometer (Partec $\mathrm{GmbH}$ ).

\subsection{Observation of chromosomes}

To determine ploidy, we performed chromosome counts using the kidney tissue from transgenic triploid carp. After culture for $1-3 \mathrm{~d}$ at $18-22^{\circ} \mathrm{C}$, the fish were injected $1-3$ times with concanavalin $(2-8 \mu \mathrm{g} / \mathrm{g}$ body weight). The interval between injections was 12-24 h. Each fish was also injected with colchicine ( $2-4 \mu \mathrm{g} / \mathrm{g}$ body weight) $2-6 \mathrm{~h}$ prior to dissecting. The kidney tissue was then removed and ground in $0.8 \% \mathrm{NaCl}$, immersed in a hypotonic solution of $0.075 \mathrm{~mol} \mathrm{~L}^{-1} \mathrm{KCl}$ at $20^{\circ} \mathrm{C}$ for $40-60 \mathrm{~min}$, then fixed in $3: 1$ methanol-acetic acid for three changes. The cells were plated on cold and wet slides and the chromosome spreads were observed and counted by Light Microscopy.

\subsection{Gonad tissue section}

We randomly sampled 20 24-month-old transgenic triploid carp and non-transgenic triploid carp from the population of hybrid progeny. In addition, we sampled 20 24-month-old diploid carp. The gonad tissue was removed from each individual and subjected to a series of steps. First, the samples were fixed in Bouin's solution, then dehydrated in alcohol, embedded in paraffin, sectioned $(6-8 \mu \mathrm{m})$, and stained with 
haematoxylin and eosin. The gonads were observed by light microscopy and some were photographed with DM6000.M. We identified the developmental stage of each sample according to the standard for Cyprinid fish in [12].

\section{Results}

\subsection{Morphological characters}

There were few obvious differences in morphology between the transgenic triploid carp (positive fish) and the non-transgenic triploid carp (negative fish) (Figure 1). Both types of triploid carp possessed a spindle-shaped body with a high dorsum and rounded abdomen. Their body color was similar, being grey-back on the dorsum and silver grey on the abdomen. The mouth was terminal with two pairs of barbels. The triploid carp possessed small, upwardly inclined eyes and triangle-shaped short gill rakers. Their bodies covered by round scales had a slightly curved complete lateral line. Compared with the crucian carp, the triploid carp had two pairs of barbels, a lower back, and the fringe of their fin rays were light red.

\subsection{Transgenic triploid carp detection}

The PCR products were separated by electrophoresis on a

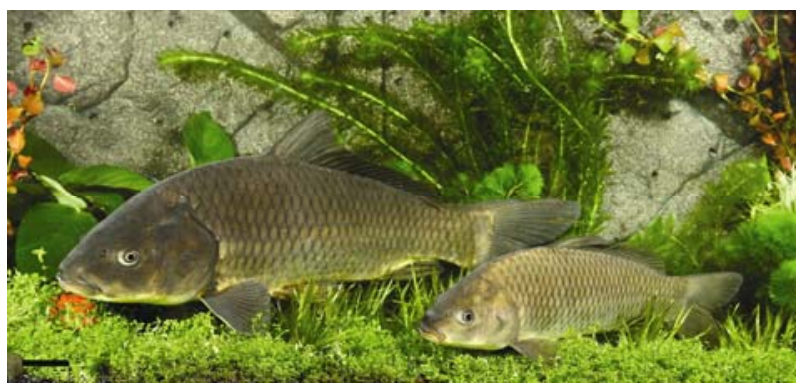

Figure 1 The appearance of the transgenic triploid carp and non-transgenic triploid carp. The transgenic triploid carp (left) and the non-transgenic triploid carp (right) in the aquarium. Scale bar=5 cm.
1.2\% agarose gel (Figure 2). A positive fragment of $328 \mathrm{bp}$ was amplified from the genomic DNA sample of the transgenic triploid carp, but not from the non-transgenic triploid carp. The 328-bp fragment was purified, cloned and sequenced. The partial sequence matched that of the grass carp growth hormone gene.

\subsection{DNA content of transgenic triploid carp}

The DNA content of the 3 groups is summarized in Table 1.

\subsection{Chromosome number of transgenic triploid carp}

The chromosome counts were performed on kidney tissue from transgenic triploid carp. The chromosome number ranged from 145 to 150 . The spreads with 150 chromosomes accounted for $88 \%$ of the 500 spreads that were counted. Thus, the triploid carp chromosome number was $3 \mathrm{n}=150$ (Figure 3 ).

\subsection{Microstructure observation on the gonads of transgenic triploid carp}

We checked several transgenic and non-transgenic triploid carp for signs of reproductive maturation at 12- and 24-months of age during the breeding seasons in April 2009 and 2010. We were unable to express semen or eggs from any fish. Conversely, both the red crucian carp and the improved tetraploid red crucian carp hybrid produced semen and eggs during the breeding season.

There were no obvious differences in the testes or ovary of the transgenic and non-transgenic forms (Figure 4). The testes from 24-month-old transgenic and non-transgenic triploid carp were classified as sterile because of the lack of mature spermatozoa. However, we did observe some understained spermatogonium-like cells and some deeply stained spermatids. The ovarian tissue of 24-month-old transgenic and non-transgenic triploid carp was classified as being in stage I and was full of oocytes suggesting the females were also sterile. In contrast, we observed a large amount of mature

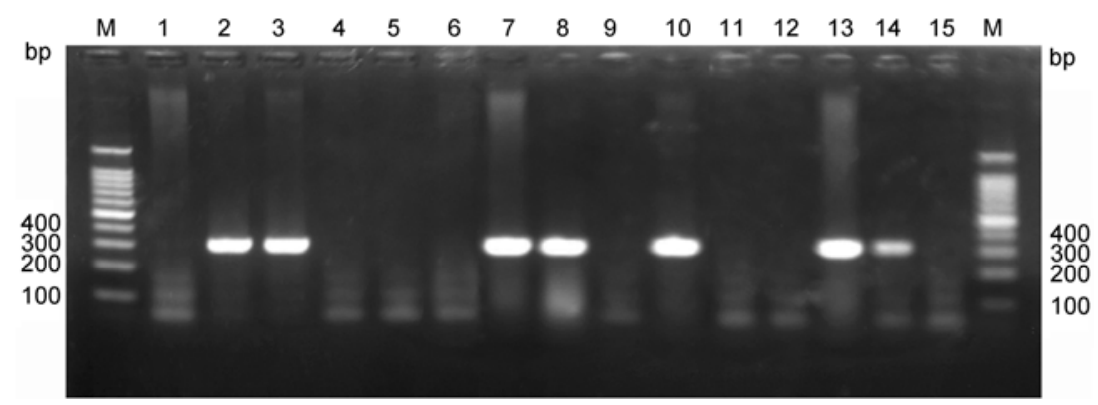

Figure 2 The results of PCR amplification using the total DNA of 15 triploid carp as the template. The positive fragments were obtained in samples 2, 3, 7, $8,10,13$ and 14. Partial sequence of grass carp growth hormone gene is shown as follows: CATTTACAGTTCAGCCATGGCTAGAGGTATGGATATGATGCTTTCTGTTGAATGTTATTTGTGGATTTAAGACTTTTTGACAACTCCTTATTTCGTTTAGATGTTTTTTTGTGCTTTCCTCTTACTTGTAAA ACTAATTTCGTAGTTGTAAAAGAGTTTATTGGAGCATGGAAAACAAAACAGATGTATTTGATCTCCAAAATCTGTTTTGATTAATCCAAAATC TTGATTTCATTGGTTATTTTATTAGGAACGATGTTGTAGATGGTAAACAAACCTCTTTCTTTTCTTCTCCTAGCATTAGTGCTGTTGTCGGTGG TGCT. 
Table 1 DNA content of diploid and triploid carp ${ }^{\text {a) }}$

\begin{tabular}{ccccc}
\hline Number & Fish sample & DNA content & Ratio & Remarks \\
\hline A & Red crucian carp & 102.55 & & \\
B & Transgenic triploid carp & 147.3 & B/A=1.44* & $P>0.5$ \\
C & $\begin{array}{c}\text { Non-transgenic } \\
\text { triploid carp }\end{array}$ & 149.7 & C/A=1.46* & $P>0.5$ \\
\hline
\end{tabular}

a) *, compared to a ratio of $1 / 1.5$, the observed ratio was not significantly different $(P>0.05)$. The triploidy of the transgenic triploid carp was confirmed by their DNA content.

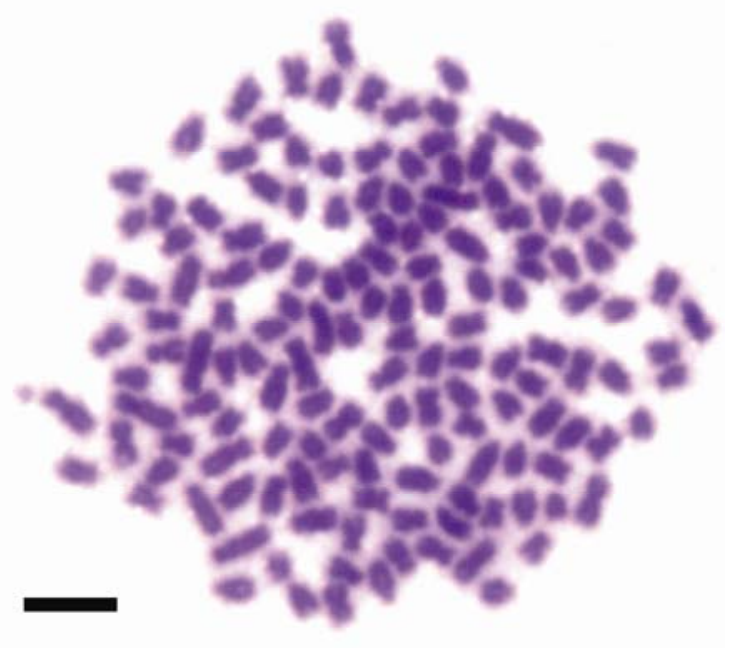

Figure 3 Chromosomes of the transgenic triploid carp. Chromosome spread of a 12-month-old transgenic triploid carp. The chromosome number was $3 \mathrm{n}=150$. Scale Bar $=4 \mu \mathrm{m}$.

spermatozoa in the testis of 24-month-old diploid carp. Similarly, the ovarian tissue of the diploid carp was steel grey and densely populated with vessels. We classified these as stage IV ovaries.

\subsection{Growth rate}

On 20 November, 253 fry of triploid carp were netted and tested for the presence of the $\mathrm{CAgcGH}$ gene using PCR. Of these, 112 were identified as transgenic triploid carp $(44.2 \%$ of the random population) and had an average body weight of $1263 \mathrm{~g}$. The remaining 141 individuals were non-transgenic triploid carp (55.8\% of the random population) that had an average body weight of $547 \mathrm{~g}$. The average body weight of the transgenic triploid carp was 2.3 times that of the non-transgenic triploid carp. The largest transgenic triploid carp individual was $2080 \mathrm{~g}$ whereas the largest non-trans- genic triploid individual was $713 \mathrm{~g}$.

\section{Discussion}

Our study is the first to document the production of transgenic triploid carp by crossing $2 \mathrm{~N}$ and $4 \mathrm{~N}$ parents. The offspring of these crosses were $100 \%$ triploid based on DNA content analysis and chromosome observations. It is possible to produce large numbers of triploid carp using this technique, thus satisfying the demands of commercial production. Previously, transgenic triploid fish have been artificially produced by physical or chemical induction. These techniques have several limitations, including an unstable introducing rate and variable induction of triploidy. Thus, it is not possible to control ecological risk or guarantee the supply of individuals for commercial aquaculture using these earlier techniques [5].

A number of researchers have documented the sterility of
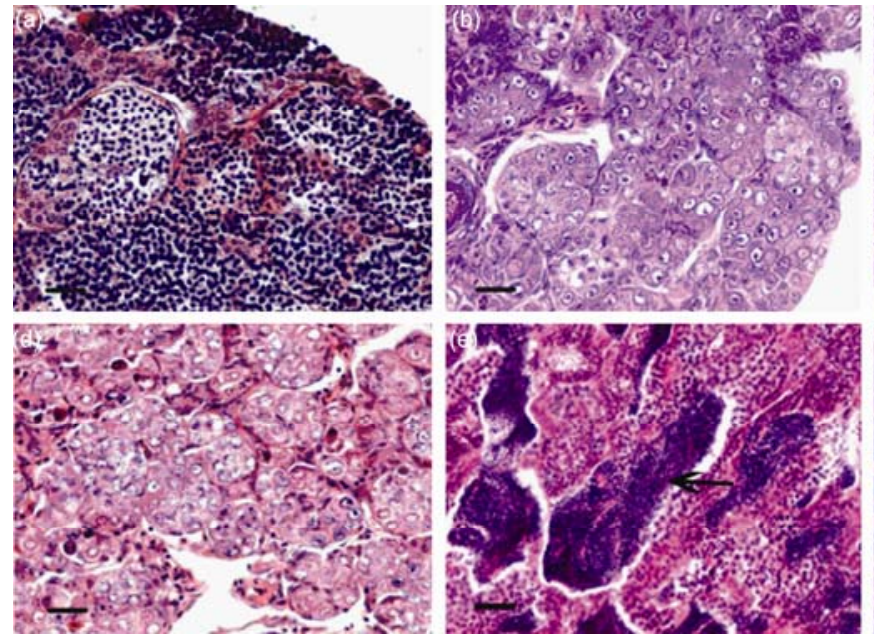

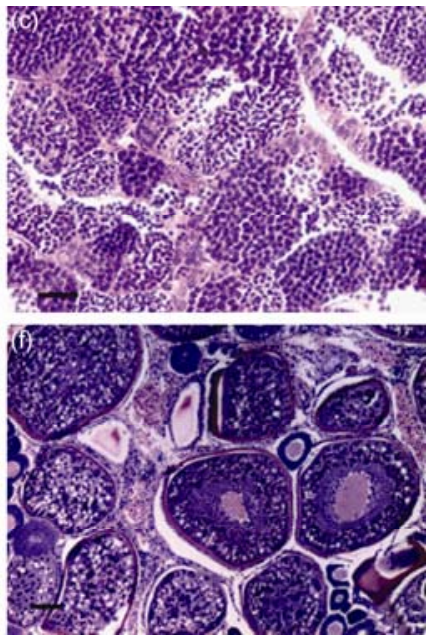

Figure 4 Triploid and diploid carp gonadal microstructure. (a) The testis of a 24-month-old transgenic triploid carp revealing the lack of mature spermatozoa in the lobules. Scale bar=10 $\mu \mathrm{m}$. (b) The ovary of a 24-month-old transgenic triploid carp in which the oocytes were all at stage II or earlier. Scale bar=10 $\mu \mathrm{m}$. (c) The testis of a 24-month-old non-transgenic triploid carp revealing the lack of mature spermatozoa in the lobules. Scale bar=10 $\mu \mathrm{m}$. (d) The ovary of a 24-month-old non-transgenic triploid carp in which the oocytes were all at stage II or earlier. Scale bar=10 $\mu$ m. (e) The testis of a 24 -month-old diploid carp. The arrow points to the large amount of mature spermatozoa in the lobules. Scale bar=10 $\mu \mathrm{m}$. (f) The stage IV ovary of a 24 -month-old diploid carp in which the cytoplasm was filled with yolk. Scale bar=50 $\mu \mathrm{m}$. 
triploid fish such as triploid carp [13], triploid catfish [14], and triploid crucian carp [11]. The triploid crucian carp were obtained by distant crossing using maternal Japanese crucian carp and paternal tetraploid crucian carp. The triploid crucian carp were allotriploid, having inherited the germ plasm from the common carp, red crucian carp, and Japanese crucian carp. Triploid crucian carp have been cultured for $\sim 20$ years with no evidence that they are able to reproduce. Typically, fertile triploid fish have been the product of gynogenesis (e.g., triploid silver carp and Japanese Guandong crucian carp (Carassius auratus langsdorfii) ) [15], not of the product of distant crossing.

Recently, we completed a comparative study of the tetraploid hybrids of red crucian carp, triploid crucian carp, and diploid red crucian carp. Based on our observations, we advance a theory to explain the mechanism of gonad abortion in triploid fish. We observed a disordered chromosome complement in the germ cells of triploid crucian carp during initial meiosis, forming 50 bivalents and 50 univalents. As a result, meiosis failed and gonadal development was stopped. During initial meiosis in the germ cells of red crucian carp and tetraploid hybrids of red crucian carp $\times$ common carp, 100 bivalents and 50 bivalents, respectively, were formed by the normal chromosome complement [16]. Based on a comparison of pituicyte ultrastructure among fish of different ploidies during the breeding season, the number of gonodotropin (GTH) secretory cells was highest in tetraploid crucian carp, followed by diploid red crucian carp, and lowest in triploid crucian carp. Similarly, in the GTH cells of the adenohypophysis, the density of secretory granules and secretory globules was highest in tetraploid crucian carp and diploid red crucian carp, and was significantly lower in triploid crucian carp [17]. Gonadotropin-releasing hormone $(\mathrm{GnRH})$, gonadotropin, and the gonadotropin receptor (GTHR) is an important part of the hypothalamus-hypophysisgonad axis. The three genes (Gnrh2, Gth and Gthr) play a role in the regulation of gonadal development. The expression of Gthr is known to be lower in the gonad of triploid crucian carp than in tetraploid crucian carp and diploid red crucian carp. Thus, the interaction between gonad GTHR and GTH release from the hypophysis is weakened, resulting in insufficient production of steroid hormones in the gonad of triploid crucian carp [18]. Accordingly, the triploid crucian carp that were obtained by crossing parents of different ploidies were rendered sterile [11,16,17] at 3 levels, chromosomal, hypophyseal, and gonadal. In this study, the transgenic triploid carp were also the product of distant-crossing hybrids that were obtained in a similar way. We did not observe mature spermatozoa, or oocytes that were beyond stage II, in any individuals during the breeding season. Similarly, we did not observe the production of sperm or eggs in any individual suggesting that all fish were sterile. In comparison, the diploid carp had large quantities of mature spermatozoa and stage IV oocytes that were full of yolk. All of the diploid carp were able to produce mature sperm or eggs.

Our results suggest that transgenic triploid carp have higher growth rates when compared to the control group under the same feeding conditions. The average body weight of the positive fish was 2.3 times of that of negative fish. The largest body weight of positive individuals was 2.91 times that of negative individuals. The increase in growth rate can be attributed to the presence of the transformed grass carp growth hormone gene which notably improved the feed conversion rate of the receptor fish. The feed conversion rates of $\mathrm{F}_{2}$ transgenic red common carp and transgenic Atlantic salmon were 10\% higher than that of the control [19]. Similarly, the conversion rates of transgenic Nile tilapia and transgenic Yellow River carp were $20 \%$ to $35 \%$ higher than that of the controls [20-22]. The feed conversion rate of 1-year-old transgenic coho salmon was 3.76 times of that of 1-year-old controls, and was 1.72 times of that of 2-year-old controls of the same body weight [3]. The feed conversion rates of transgenic mud loach (Misgurnus mizolepis) and transgenic tilapia (Oreochromis sp.) were also improved by 1 and 1.9 times, respectively $[23,24]$.

Most of the measurable ratios characterizing the transgenic triploid carp were intermediate between those of the paternal diploid carp and maternal tetraploid crucian carp. The morphology of the transgenic crucian carp appeared normal and there were no obvious differences in the morphology of the transgenic triploid carp and the non-transgenic triploid carp. We did not observe malformed fish in the triploid population.

Our study was based on established populations of improved tetraploid red crucian carp hybrids and transgenic diploid Yellow River carp, the crossing of which produced $100 \%$ triploid offspring. The paternal transgenic diploid Yellow River carp were heterozygotes. Both transgenic and non-transgenic triploid hybrids were obtained from the crosses, providing a comparative system to study the biological characteristics of both kinds of fish. We crossed homozygote transgenic diploid carp with the improved tetraploid red crucian carp hybrid during the 2010 breeding season. In theory, we expect the progeny to be $100 \%$ transgenic triploid carp.

In conclusion, transgenic triploid carp have maintained the sterile characteristic of triploid hybrid fish but have a faster growth rate and a higher feed conversion rate. The use of sterile transgenic triploid carp poses significantly less risk to the environment but offers a number of benefits to commercial growers.

This work was supported by the National Key Basic Research Program of China (2007CB109206) and the National Special Fund for Research in Public Welfare Sector (200903046-08).

1 Maclean N, Laight R J. Transgenic fish: An evaluation of benefits and risks. Fish Fisher, 2000, 1: 146-172

2 Wang Y P, Hu W, Wu G, et al. Genetic analysis of "all-fish" growth 
hormone gene transferred carp (Cyprinus carpio L.) and its F1 generation. Chinese Sci Bull, 2001, 46: 1174-1178

3 Devlin R H, Biagi C A, Yesaki T Y. Growth, viability and genetic characteristics of $\mathrm{GH}$ transgenic coho salmon strains. Aquaculture, 2004, 236: 607-632

4 Fletcher G L, Shears M A, Yaskowiak E S, et al. Gene transfer: Potential to enhance the genome of Atlantic salmon for aquaculture. Aus J Exp Agricul, 2004, 44: 1095-1100

$5 \mathrm{Hu}$ W, Wang Y P, Zhu Z Y. Progress in the evaluation of transgenic fish for possible ecological risk and its containment strategies. Sci China Ser C-Life Sci, 2007, 50: 573-579

6 Liu S J, Liu Y, Zhou G J, et al. The formation of tetraploid stocks of red crucian carpxcommon carp hybrids as an effect of interspecific hybridization. Aquaculture, 2001, 192: 171-186

7 Sun Y D, Liu S J, Zhang C, et al. The chromosome number and gonadal structure of F9 F11 tetraploid crucian-carp. Acta Genet Sin, 2003, 30: 414-418

8 Liu S J. Distant hybridization leads to different ploidy fishes. Sci China Life Sci, 2010, 53: 416-425

9 Wang J, Qin Q B, Chen S, et al. Formation and biological characterization of three new types of improved crucian carp. Sci China Ser C-Life Sci, 2008, 51: 544-551

10 Liu S J, Sun Y D, Zhang C, et al. Production of gynogenetic progeny from tetraploid hybrids red crucian carp $\times$ common carp. Aquaculture, 2004, 236: 193-200

11 Liu S J, Hu F, Zhou G J, et al. Gonadal structure of triploid crucian carp produced by crossing tetraploid hybrids of Carassium auratus red var. ( $(+) \times$ Cyprinus carpio ( $\left.\sigma^{\top}\right)$ with Japanese crucian carp (Carassius auratus cavieri t. et s). Acta Hydrobiol Sin, 2000, 24: 301-306

12 Liu Y. Breeding Physiology of Chinese Cultivated Fish. Beijing: Agricultural Publishing House, 1993. 22-30

13 Gervai J, Peter S, Nagy A, et al. Induction triploidy incarp, Cyprinus carpio L. J Fish Biol, 1980, 17: 667-671
14 Yin H B, Sun Z W, Pan Z W, et al. Study on gonadal development of triploid catfish (Silurus asotus L.). Oceanol Limnol Sin, 2000, 31: 123-129

15 Wu Q J, Gui J F. Fish Genetic Breeding Engineering. Shanghai: Shanghai Sicentific and Technology Press, 1999. 40-41

16 Zhang C, He X X, Liu S J, et al. The chromosome pairing in meiosis $\mathrm{I}$ in tetraploid hybrids and all triploid Crucian Carp. Acta Zool Sin, 2005, 51: 89-94

17 Long Y, Liu S J, Huang W R, et al. Comparative studies on histological and ultra-structure of the pituitary of different ploidy level fishes. Sci China Ser C-Life Sci, 2006, 49: 446-453

18 Long Y, Liu S J, Zhong H, et al. The distinct expression of Gnrh, Gth $\beta$ and $G t h r$ gene in sterile triploids and fertile tetraploids. Cell Tissue Res, 2009, 338: 151-159

19 Cook J T, McNiven M A, Richardson G F, et al. Growth rate, body composition and feed digestibility/conversion of growth enhanced Atlantic salmon (Salmo salar). Aquaculture, 2000, 188: 15-32

20 Rahman M A, Ronyai A, Engidaw B Z, et al. Growth and nutritional trials of transgenic Nile tilapia containing an exogenous fish growth hormone gene. J Fish Biol, 2001, 59: 72-78

21 Fu C, Li D, Hu W, et al. Growth and energy budget of $F_{2}$ "all-fish" growth hormone transgenic common carp. J Fish Biol, 2007, 70: 347-361

22 Kobayashi S, Alimuddin Morita T, Miwa M, et al. Transgenic Nile tilapia (Oreochromis niloticus) over-expressing growth hormone show reduced ammonia excretion. Aquaculture, 2007, 270: 427-435

23 Nam Y K, Noh J K, Cho Y S, et al. Dramatically accelerated growth and extraordinary gigantism of transgenic mud loach (Misgurnus mizolepis). Transgenic Res, 2001, 10: 353-362

24 Martinez R, Juncal J, Zaldivar C, et al. Growth efficiency in transgenic tilapia (Oreochromis sp.) carrying a single copy of an homologous cDNA growth hormone. Biochem Biophys Res Commun, 2000, 267: 466-472

Open Access This article is distributed under the terms of the Creative Commons Attribution License which permits any use, distribution, and reproduction in any medium, provided the original author(s) and source are credited. 